\title{
Time-invariance and geographical divide of earthquake mortality in Italy since $\mathbf{1 8 0 0}$
}

\author{
Pier Luigi Bragato*, Carla Barnaba, Chiara Scaini and Monica Sugan \\ National Institute of Oceanography and Applied Geophysics - OGS
}

Article history: received January 8, 2020; accepted June 12, 2020

\begin{abstract}
We considered the mortality data of the earthquakes which occurred in Italy since 1800 and investigated their spatial-temporal characteristics. For this purpose, we developed a log-linear regression model relating the number of deaths to the magnitude of the earthquakes and analyzed the distribution of the residuals from the model. We found that, for fixed magnitude, the mortality of the earthquakes of the last decades is almost identical to that of the $19^{\text {th }}$ century despite the fact that the population is decreasing in the small municipalities with high seismic hazard. There is also a geographical divide: for the same magnitude, an earthquake in southern Italy causes 2.9 times the number of victims than in northern Italy. The gap is partially justified by the higher population density in the seismic areas of southern Italy, while it does not seem to depend on seismological factors (seismic source, regional attenuation and site effects). The north/south divide increases to a factor of 8.3 for the earthquakes occurring between 00:00 and 05:00 a.m., when most people are sleeping and rely almost entirely on the strength of their houses for survival. We suggest that differences in the quality and maintenance level of the residential buildings are the primary factors determining this geographic divide, supported by data from a survey taken in 1934 and from the last general national census of 2011. Our results indicate that the situation of residential buildings in Italy requires a strict application of the seismic regulations as well as their extension to stimulate the correct maintenance and retrofitting of the existing buildings.
\end{abstract}

Keywords: seismic risk, seismic regulation, building maintenance, north/south divide, small-town depopulation.

\section{Introduction}

In recent years, three earthquakes of magnitude between 6.1 and 6.3 struck northern and central Italy, causing more than 600 victims and heavy socio-economic consequences in the epicentral areas: the 2009 LAqquila earthquake (moment magnitude Mw 6.3, 309 deaths); the 2012 Emilia earthquake (Mw 6.1, 26 deaths) and the 2016 Central Italy earthquake (Mw 6.2, 299 deaths). The severity of the consequences compared to the relatively moderate size of the earthquakes has highlighted once more the extreme seismic vulnerability of the country and put into question the effectiveness of seismic risk mitigation actions and legislation implemented in Italy through its history [Bellicoso, 2011]. In particular, we recall that the first Italian earthquake-resistant design was issued in 1909 [Royal Decree No. 193 of 18 April], as a consequence of the catastrophic earthquake of Calabria-Messina in 1908 (more than 80,000 deaths). For the first time, the seismic zones were identified in Italy, even if it was no more than a map of 


\section{Pier Luigi Bragato et al.}

the territories hit by strong earthquakes in the regions of Calabria e Sicily. The 1909 Regulation formed the basis for the subsequent building codes up to 1974, but it was only after the Friuli (1976) and Irpinia (1980) earthquakes that seismic classification was linked to further seismological knowledge and based on a probabilistic approach. Since then, $45 \%$ of the national territory has been classified into three hazard categories where specific regulations have become mandatory for new buildings. This classification remained in force until 2003, when with the Ordinance of the President of the Council of Ministers n. 3274 the entire national territory was reclassified into four areas of decreasing danger, enumerated from 1 to 4 . Also in this case, the introduction of a new seismic building code was accelerated by the occurrence of an earthquake (2002, Molise earthquake, magnitude Mw 5.7) and its tragic impacts (the collapse of a school killing 26 schoolchildren and one teacher). Looking at the data collected during the last general national census [ISTAT, 2011a], about $47 \%$ of the residential buildings (hosting about $37 \%$ of families) were built less than 50 years ago and should therefore comply with some type of building code, which should guarantee better quality than in the past, with consequent risk reduction of human lives. Unfortunately, this theory contrasts with the situation evidenced by the recent earthquakes, during which even modern buildings suffered heavy damage. In fact, in addition to old masonry buildings, many post-war reinforced concrete buildings are below current standards today [Spence, 2007]. Finally, it is worth mentioning that the building code introduced in 2003 has suffered some delays in its application, during which the older regulation was still in force [Spence, 2007].

In the present work we investigated the factors affecting earthquake mortality in Italy since 1800. In general, the number of deaths caused by an earthquake depends on various elements [Coburn et al. 1992; Gutiérrez et al. 2005; Bilham 2009; Alexander and Magni 2013]. Some of them are of seismological nature: the magnitude of the event, the geometry of the seismic source, the characteristics of propagation and the geological conditions near the surface. Other factors relate to the characteristics of the buildings: quality of materials, age, and maintenance level [Guidoboni and Ferrari, 2000]. Alexander and Magni [2013] stress the importance of human behavior during the shaking, which is also related to the gender and age of the people involved (for example, women and the elderly are most at risk). Finally, population density plays an important role, as well as the time of the day at which the earthquake occurs (people are less reactive at night and mainly concentrated in residential buildings, which, as shown in the following, does not necessarily imply higher mortality). Despite the complex interaction of these heterogeneous elements, the number of victims constitutes a basic and clear indicator of the severity of an earthquake, also useful for investigating social aspects [Ambraseys and Bilham, 2011]. For our study in Italy, we exploited a well-consolidated catalog [Guidoboni et al., 2018, 2019] restricted to the last two centuries to guarantee a sufficiently reliable estimation of the number of victims. We analyzed the spatial-temporal characteristics of earthquake lethality after accounting for the different magnitude of the events. In particular, we focused on the following factors: trend of seismicity at the national level (decreasing over the last century); geographical distribution of the earthquakes; demographic evolution of the country; geophysical characteristics of the earthquakes (source and propagation); night/day lethality. The results of the analysis underline the main factors that influence mortality during earthquakes and contribute to partially explaining the mortality trends in the past two centuries in Italy. In particular, they lead to a discussion on the quality of buildings in Italy and its evolution over time.

\section{Data}

We analyzed the earthquakes which occurred in Italy in the time period 1800-2018. For the events from 1800 to 1997 we used the catalog CFTIMed5 [Guidoboni et al., 2018, 2019] that collects, for each earthquake, both the seismological parameters (time of the earthquake, epicentral coordinates and moment magnitude $\mathrm{Mw}$ ) and the number of casualties. The data set was completed until 2018 with the instrumentally-derived seismological parameters of the European-Mediterranean Regional Centroid Moment Tensor (RCMT) Catalog [Pondrelli et al., 2011] and the estimation of the number of victims published at the internet site of the Italian Civil Protection Department (www.protezionecivile.gov.it/attivita-rischi/rischio-sismico/emergenze). The epicentral coordinates and the magnitudes reported in CFTIMed5 were computed with the Boxer method [Gasperini et al., 1999], a robust algorithm that considers the entire macroseismic intensity field. In particular, the reported magnitude is an indirect estimation of the moment magnitude $\mathrm{Mw}$, with the algorithm calibrated on instrumental measurements available since 1976. The values of Mw have been recently revised for the 2.0 version of another Italian seismic catalog, named 
CPTI15 [Rovida et al., 2019, 2020]. For the earthquakes considered here, the mean difference of magnitude between the two catalogs is $0.00 \pm 0.14$. Some tests performed using the new set of magnitudes confirm the main results of the analysis presented here.

As for seismic sequence, the CFTIMed5 catalog assigns the number of victims cumulatively to the entire sequence, with no distinction between the fatalities of the main shock and those of the aftershocks. In this case we attributed all the victims to the main shock. We excluded two earthquakes of magnitude 5.6 for which the catalog reports "some victims" from the analysis (1836 Venetian Prealps and 1870 Romagna), and one of magnitude 5.7 for which the catalog reports "many victims" (1978 Gulf of Patti, northeastern Sicily). In these three cases the available sources of information seem to indicate less than ten casualties. We excluded the earthquakes in volcanic areas because they are usually very shallow and can induce a peak of damage and mortality in the epicentral area even at low magnitudes. This is the case of three earthquakes which occurred at Casamicciola Terme (Island of Ischia, Gulf of Naples) in 1881 (127 victims, Mw 5.4 revised to Mw 4.14 in CPTI15v2), 1883 (2333 victims, Mw 5.7, revised to Mw 4.26 in CPTI15v2) and 2017 (2 victims, Mw 4.0).

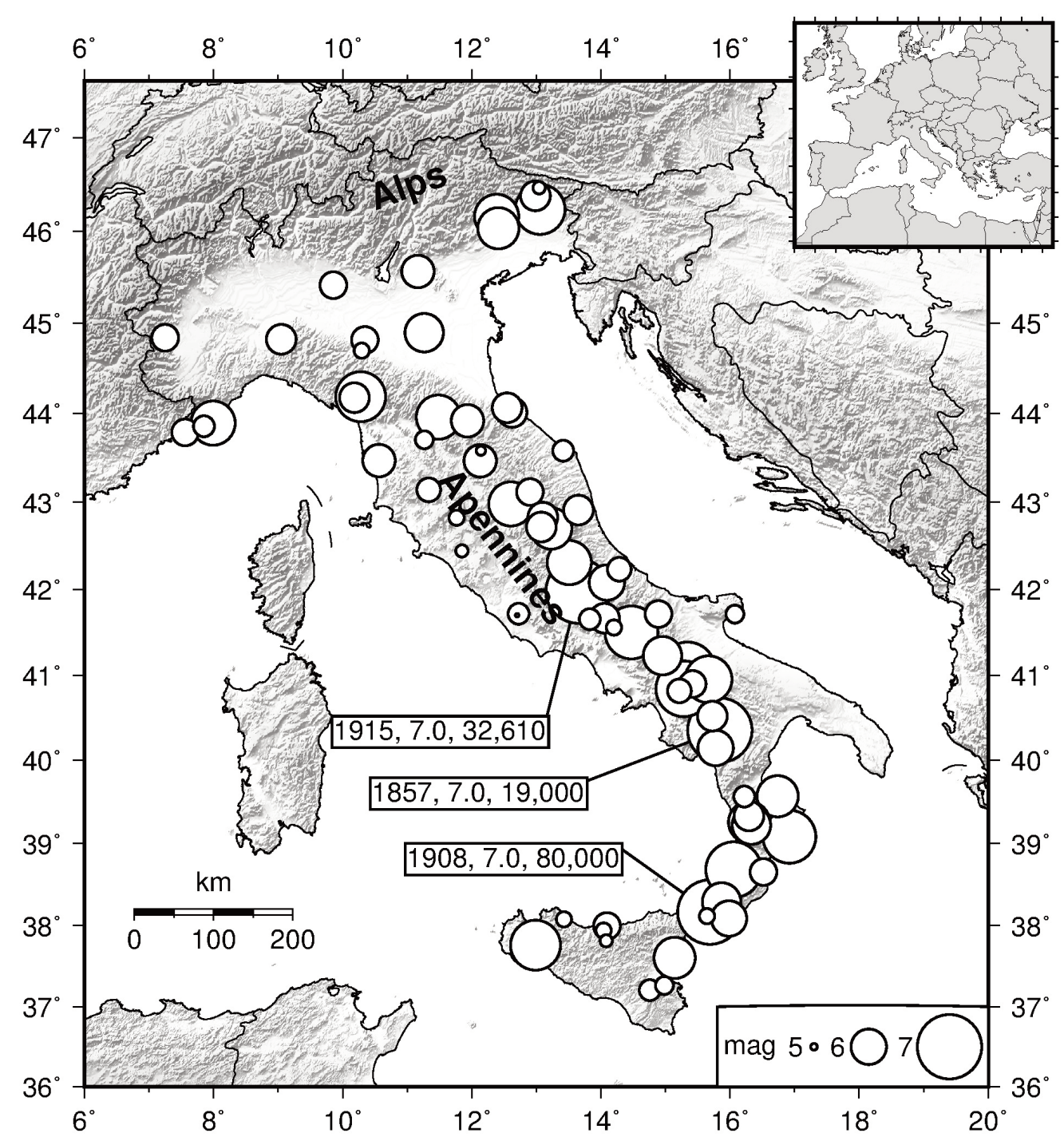

Figure 1. Epicenters of the earthquakes with victims occurred in Italy since 1800. Earthquakes in volcanic areas (Island of Ischia and Mt. Etna) are excluded. The dimension of the circles is proportional to the magnitude. The labels refer to the three earthquakes that caused more than 10,000 victims (all of magnitude Mw 7.0): 1857, Basilicata earthquake (19,000 casualties); 1908, Calabria-Messina earthquake (80,000 casualties); 1915 Marsica earthquake (32,610 casualties). 


\section{Pier Luigi Bragato et al.}

The selected data set includes 76 earthquakes with magnitude Mw between 4.9 and 7.0 (epicenters in Figure 1). The highest number of victims (80,000) was reached in the Calabria-Messina earthquake of 1908 (Mw 7.0), when the effect of the shaking was combined with that of a tsunami. Other major earthquakes are those of 1915 in Marsica and 1857 in Basilicata (both of magnitude Mw 7.0, with 32,610 and 19,000 victims, respectively). The three earthquakes are shown in Figure 1. The same figure illustrates the spatial distribution of all the selected earthquakes: the largest part of them is located along the Apennines, while two additional clusters are found in the northeastern Alpine area and in Sicily. Figure 2 shows the time evolution of the events in terms of casualties (Figure 2a), magnitude (Figure 2b) and cumulative number of victims and released energy (Figure 2c). Figure 2c shows two major steps in the cumulative number of casualties around 1850 and 1910. During the last century (Figure 3), the seismicity is characterized by a marked decreasing trend with a reduction of both the number of victims and of the released energy. In particular, Figure $3 \mathrm{c}$ shows three major steps: at the beginning of the $20^{\text {th }}$ century, in the time interval 1960-1980, and more recently, with a further increasing phase opened by the L'Aquila earthquake of 2009 and continued with the Emilia earthquake of 2012 and the Central Italy earthquake of 2016. The alternate behavior of Figure 2 and Figure 3, with the time clustering of earthquakes at the national level, has been analyzed by Bragato [2017b], who recognized a significant periodicity with cycles of about 46 years. Furthermore, the decrease of the last century [Bragato and Sugan, 2014] seems to indicate the conclusion of a seismic transient that struck Italy starting in the $17^{\text {th }}$ century [Bragato, 2017a]. Such a countrywide transient was initially pointed out by Stucchi et al. [2011] and assessed accurately by Bragato [2017a]. It has a time correspondence with the volcanic activity in Italy, especially in the area of Naples [Bragato, 2015, 2018], and has been interpreted as the expression of large-scale triggering processes, possibly related to the increased atmospheric precipitation during the Little Ice Age [Bragato and Holzhauser, 2019].

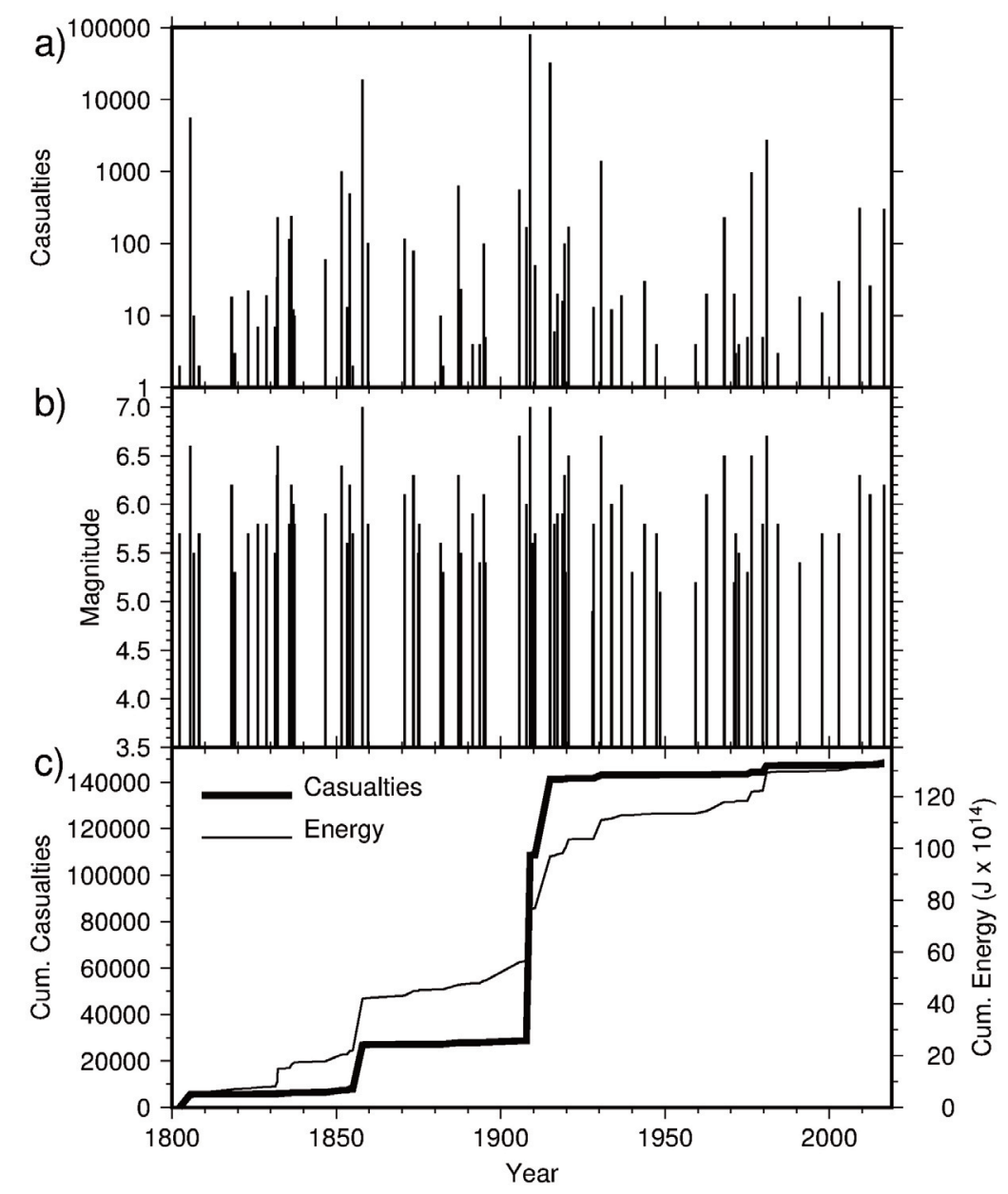

Figure 2. Time evolution of seismicity with victims in Italy since 1800: a) number of casualties for each earthquake; b) magnitude of the earthquakes; c) cumulative number of casualties and cumulative released energy. 


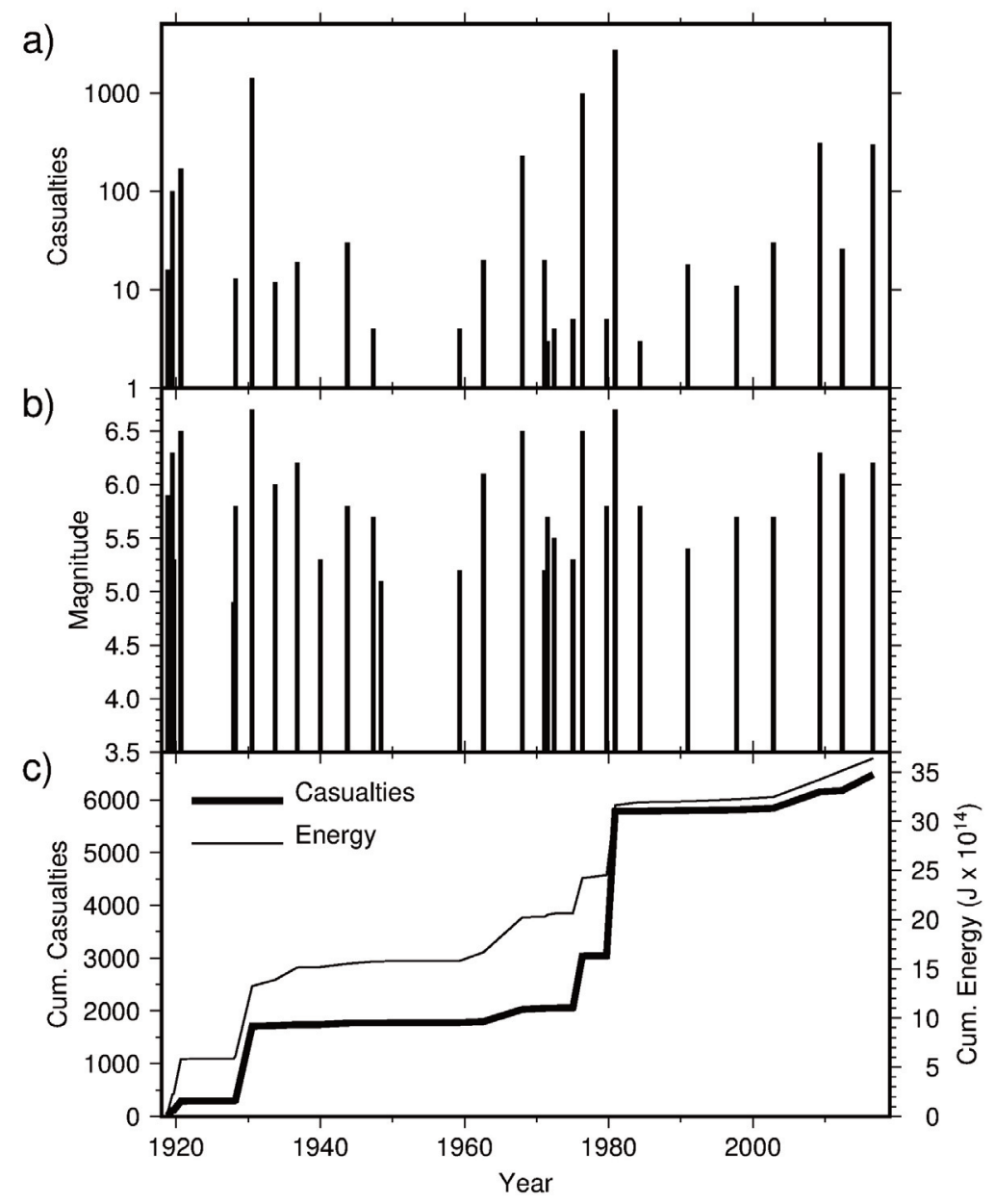

Figure 3. Time evolution of seismicity with victims in Italy since 1918: a) number of casualties for each earthquake; b) magnitude of the earthquakes; c) cumulative number of casualties and cumulative released energy.

\section{Analysis}

As a first step we explored the relationship between the magnitude of the earthquakes and the number of casualties by estimating the parameters of the log-linear regression model

$$
\log _{10}(N c)=a+b M_{W}
$$

(Nc number of casualties; Mw moment magnitude of the earthquake), obtaining the results reported in Tab.1 (model number 1). Figure 4a shows the data and the resulting regression line. The distribution of the residuals around the line (gray bars in Figure $4 \mathrm{~b}$ ) is quite large (standard deviation of residuals $\sigma_{\text {res }}=0.56$, corresponding to the multiplicative factor 3.5 for the number of casualties). Furthermore, the distribution appears bimodal with peaks near the values -0.5 and 0.5 , respectively. The bimodality is marked for the strongest earthquakes (magnitude larger or equal to 6, white bars in Figure 4b) and is not eliminated even by using more complex linear or non-parametric regression models. This characteristic suggests the existence of two classes of earthquakes, class A and class B, where on average, for the same magnitude, an earthquake of class A causes about 10 times the victims of an earthquake in class B. In order to explore the nature of this bimodality we searched the optimal partition of the earthquakes in the two classes using the model

$$
\log _{10}(N c)=a+b M_{W}+c I, I=\left\{\begin{array}{l}
1 \text { for earthquakes in class A } \\
0 \text { for earthquakes in class B }
\end{array}\right.
$$



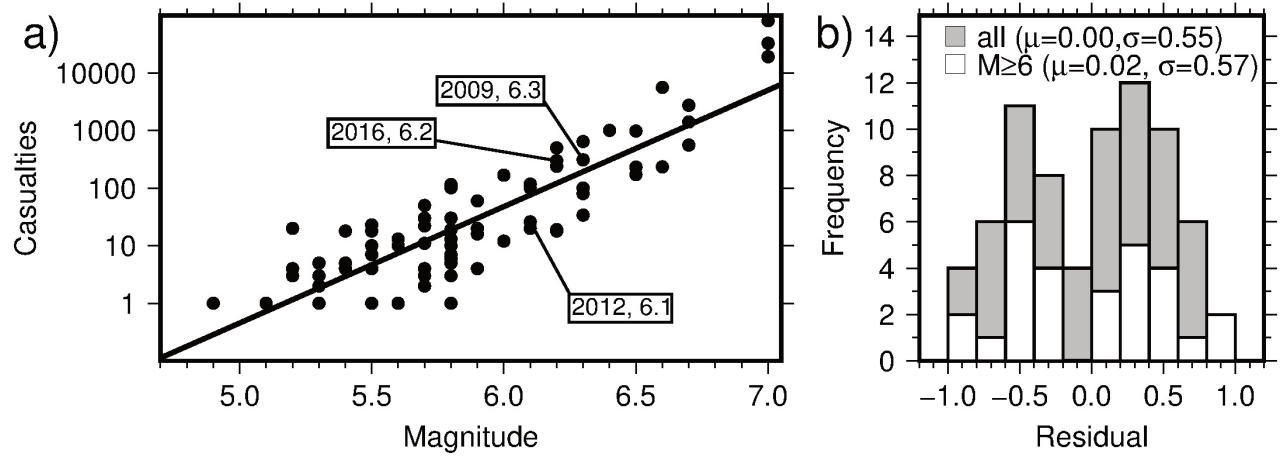

Figure 4. Relationship between magnitude and number of casualties for the earthquakes occurred in Italy since 1800: a) data points and log-linear model estimated according to equation 1 ; b) distribution of the corresponding residuals for the entire data set (grey bars) and for magnitude larger or equal to 6 (white bars) with the indication of mean and standard deviation ( $\mu$ and $\sigma$, respectively).
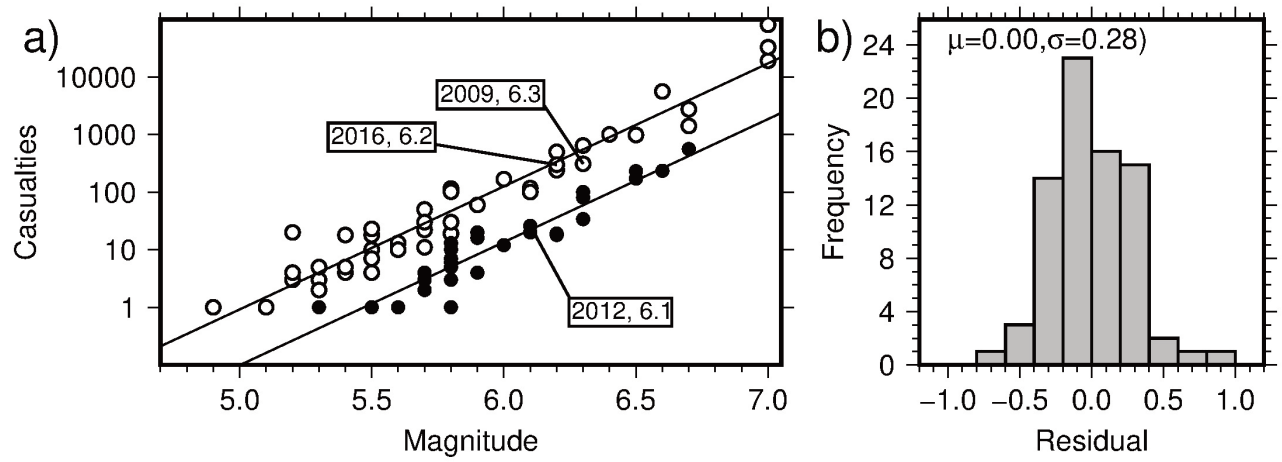

Figure 5. Relationship between magnitude and number of casualties for the earthquakes occurred in Italy since 1800: a) data points and parallel regression lines obtained for the two-class model of equation 2 (white circles: class-A earthquakes; black circles: class-B earthquakes); b) distribution of the corresponding residuals with the indication of mean and standard deviation ( $\mu$ and $\sigma$, respectively).

comprising two parallel straight lines separated by the distance $c$. An earthquake is included in class A if the corresponding residual $\log _{10}(N c)_{\text {observed }}-\log _{10}(N c)_{\text {estimated }}$ computed for the model of equation 1 is larger than a given separation value $\mathrm{x}_{\text {part }}$, otherwise it is included in class $\mathrm{B}$. By regression, we estimated the parameters of equation 2 trying different partitions of the earthquakes (defined by different $\mathrm{x}_{\mathrm{part}}$ values) and selected the best separation value based on the minimization of the residual variance. The optimal separation occurred for $\mathrm{x}_{\text {part }}=-0.07$ with the estimated regression parameters reported in Table 1 (model number 2). The parallel regression lines are shown in Figure $5 \mathrm{a}$. With the introduction of the two classes the distribution of the residuals becomes unimodal (Figure $5 \mathrm{~b}$ ) and the standard deviation is halved $\left(\sigma_{\mathrm{res}}=0.28\right)$. The distance between the two lines is quite large, with $c=0.97 \pm 0.07$ (Table 1, model number 2). This means that on average, for a fixed magnitude, an earthquake in class A causes 9.3 times the number of victims of an earthquake in class B. For a formal assessment of the relative quality of the two models (with and without classes), it is necessary to refer to model selection criteria such as the Bayesian Information Criterion (BIC) [Schwarz 1978] and the Akaike Information Criterion (AIC) [Akaike 1977]. According to both BIC and AIC, the inclusion of more parameters in a model is justified only if they significantly improve the fit. For cases such as those discussed here, when the ratio between the number of data and the number of parameters is lower than 40 , Burnham and Anderson [2002] suggest using the AIC corrected for small sample sizes, denoted AICc: 


$$
\operatorname{AICc}\left(\hat{L}, k, N_{o b s}\right)=-2 \ln (\hat{L})+2 k+2 k(k+1) /\left(N_{o b s}-k-1\right)
$$

where $k$ is the number of estimated parameters, $N_{o b s}$ is the number of observations and $\ln (\hat{L})$ is the log-likelihood of the model. For linear regression it is [Taboga, 2012]:

$$
\ln (\hat{L})=-\frac{N_{o b s}}{2} \ln (2 \pi)-\frac{N_{o b s}}{2} \ln \left(\sigma^{2}\right)-\frac{1}{2 \sigma^{2}} \sum_{1=1}^{N_{o b s}} r_{i}^{2}
$$

where $r_{\mathrm{i}}$ is the residual $\log _{10}(N c)_{\text {observed }}-\log _{10}(N c)_{\text {estimated }}$ for the $\mathrm{i}$-th earthquake (we obtained the log-likelihood of our models using the "logLik" function of the R software, [R Core Team 2017]). When comparing different models estimated for the same data set, that with lowest AICc is preferred. In the present case, $k=3$ for the basic model of equation 1 ( $a, b$ and the residual variance), and $k=4$ for the two-class model of equation 2 . It can be argued that in the latter case also the choice of the classification threshold $x_{\text {part }}$ is part of the model, so that $k=5$. Even assuming $k=5$, the two-class model is preferred as it has $A I C c=30.9$ compared to $A I C c=131.0$ for the basic model (models 1 and 2 in Table 1). The analysis was completed considering a model with interaction, where the class also affects the slope of the straight lines:

$$
\log _{10}(N c)=a+b M_{W}+c I+d M_{W} I, I=\left\{\begin{array}{l}
1 \text { for earthquakes in class A } \\
0 \text { for earthquakes in class B }
\end{array}\right.
$$

where A and B are the same optimal classes as before. As shown in Table 1 (model number 3), the slope difference is not significant $(d=0.06 \pm 0.17)$ and the model is judged as not optimal according to the AICc criterion.

\begin{tabular}{|c|c|c|c|c|c|c|c|c|c|}
\hline $\begin{array}{c}\text { n. } \\
\text { model }\end{array}$ & $\begin{array}{c}\text { model/ } \\
\text { classification } \\
\text { type }\end{array}$ & $\begin{array}{l}\text { n.eqs. } \\
\text { each class }\end{array}$ & $\mathbf{a}$ & b & c & d & $\sigma_{\text {res }}$ & $\begin{array}{c}\mathbf{k} \\
\mathbf{f r e e} \\
\text { parameters }\end{array}$ & AICc \\
\hline 1 & $\begin{array}{c}\text { no class } \\
\text { (eq. 1) }\end{array}$ & 76 & $-10.44 \pm 0.80$ & $2.02 \pm 0.14$ & - & - & 0.56 & 3 & 131.0 \\
\hline 2 & $\begin{array}{c}\text { A/B } \\
\text { one slope } \\
\text { (eq. 2) }\end{array}$ & $44 / 32$ & $-11.68 \pm 0.41$ & $2.14 \pm 0.07$ & $0.97 \pm 0.07$ & - & 0.28 & 5 & 30.9 \\
\hline 3 & $\begin{array}{c}\text { A/B } \\
\text { two slopes } \\
\text { (eq. 5) }\end{array}$ & $44 / 32$ & $-11.40 \pm 0.87$ & $2.09 \pm 0.15$ & $0.61 \pm 0.98$ & $0.06 \pm 0.17$ & 0.28 & 6 & 33.1 \\
\hline 4 & $\begin{array}{l}\text { north/south } \\
\text { one slope } \\
\text { (eq. } 2 \text { ) }\end{array}$ & $29 / 47$ & $-10.50 \pm 0.73$ & $1.98 \pm 0.12$ & $0.47 \pm 0.12$ & - & 0.51 & 5 & 121.5 \\
\hline 5 & $\begin{array}{l}\text { north/south } \\
\text { two slopes } \\
\text { (eq. 5) }\end{array}$ & $29 / 47$ & $-9.29 \pm 1.54$ & $1.77 \pm 0.26$ & $1.10 \pm 1.75$ & $0.27 \pm 0.30$ & 0.51 & 6 & 123.1 \\
\hline
\end{tabular}

In the following sub-sections we analyze some of the factors that might explain the observed bimodality of data as well as the residual variance.

Table 1. Results of log-linear regression according to equations 1, 2 and 5 for different types of earthquake classification (no classification, arbitrary optimal A/B classification, and north/south classification). The models are enumerated from 1 to 5 for reference. 


\section{Pier Luigi Bragato et al.}

\subsection{Direct cause of mortality}

Almost all the victims of the Italian earthquakes are caused by the collapse of buildings. The only case of strong tsunami is that induced by the 1908 Calabria-Messina earthquake, which could have killed 2,000 people out of a total of 80,000 victims [Boschi et al., 1995]. Casualties due to heart attacks, accidents during attempts to escape or landslides are sometimes reported, but they are a very small minority. These elements led to the conclusion that the bimodality of the residuals is not an effect of different causes of mortality.

\subsection{Geographical dependence}

An alternative suggestion for the explanation of the bimodality comes from the geographical distribution of the events in each class, shown in Figure 6a. The map depicts an unbalanced distribution of class-B, less lethal earthquakes, predominant in the northern part. According to Figure $6 \mathrm{~b}$ the north/south difference is even more evident for $\mathrm{Mw} \geq 6$ earthquakes. To assess the north/south mortality gap, we estimated the two-class regression model of equation 2 considering the earthquakes located north and south of $42.95^{\circ} \mathrm{N}$. In particular, we looked at the distance between the two parallel regression lines (parameter c in equation 2). The results are reported in Table 1 (model 4): based on the AICc, the model with north/south classification is preferred to the basic model of equation 1 (AICc=121.5 instead of 131.0). The distance between the north/south classes is $\mathrm{c}=0.47 \pm 0.12$ (significant at the 0.01 level, model 4 in Table 1), corresponding to a mortality that is 2.9 times larger in southern Italy. That is, a geographical divide explains a significant part of the bimodal distribution of residuals (Figure $4 \mathrm{~b}$ ), although other important factors should be involved (recall that the separation was $\mathrm{c}=0.97$ for the arbitrary A/B classification performed before). A model with north/south classification and class-dependent slope (equation 4 ) has also been attempted but rejected based on AICc (model 5 in Table 1).
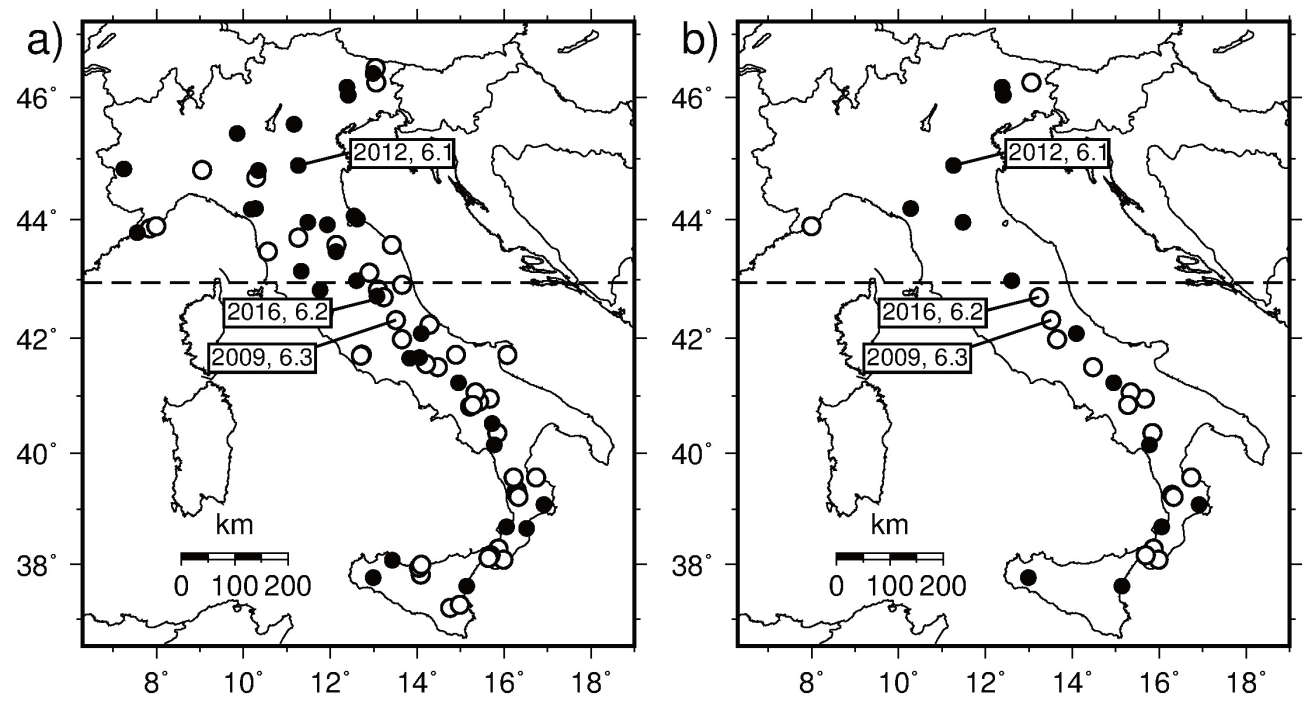

Figure 6. Epicenters of the earthquakes with victims occurred in Italy since 1800. The filling is the same of Figure 5a (white circles: class-A earthquakes; black circles: class-B earthquakes): a) entire data set; b) earthquakes with $\mathrm{M} \geq 6$.

\subsection{Effects of geophysical and geological conditions}

Having identified a geographical divide in earthquake mortality, we explored its possible dependence on the systematic differences of the physical properties of the earthquakes occurring in northern and southern Italy 
(seismic source, regional attenuation and site effects). In the absence of detailed studies at the national level, some general indications can be extracted from the existing literature on regionalized ground-motion predictive equations. In their basic form, these equations account for the scaling with increasing magnitude and the attenuation with distance. At short distances (up to 10-20 km) the regionalized models should roughly account for systematic differences of the seismic sources (e.g. average hypocentral depth and the predominant type of focal mechanism), while at longer distances they should reflect differences of the regional attenuation. Both Michelini et al. [2008] and Bragato [2009] propose a partition of the Italian territory in a few areas characterized by different seismic behavior. The first work uses six areas (polygons delimited by black lines in Figure 7) pre-determined on the basis of tectonic and geophysical considerations. The second work recognizes four zones (gray areas numbered from 1 to 4 in Figure 7) based on the optimization of the predictive equations. The two works find significant regional differences, but they are not correlated with the geographical divide of earthquake mortality data. In particular, there is no significant difference across the limit of $42.95^{\circ} \mathrm{N}$ (see the polygon labeled APE drawn from [Michelini et al., 2008], and the gray area number 2 drawn by Bragato [2009]).

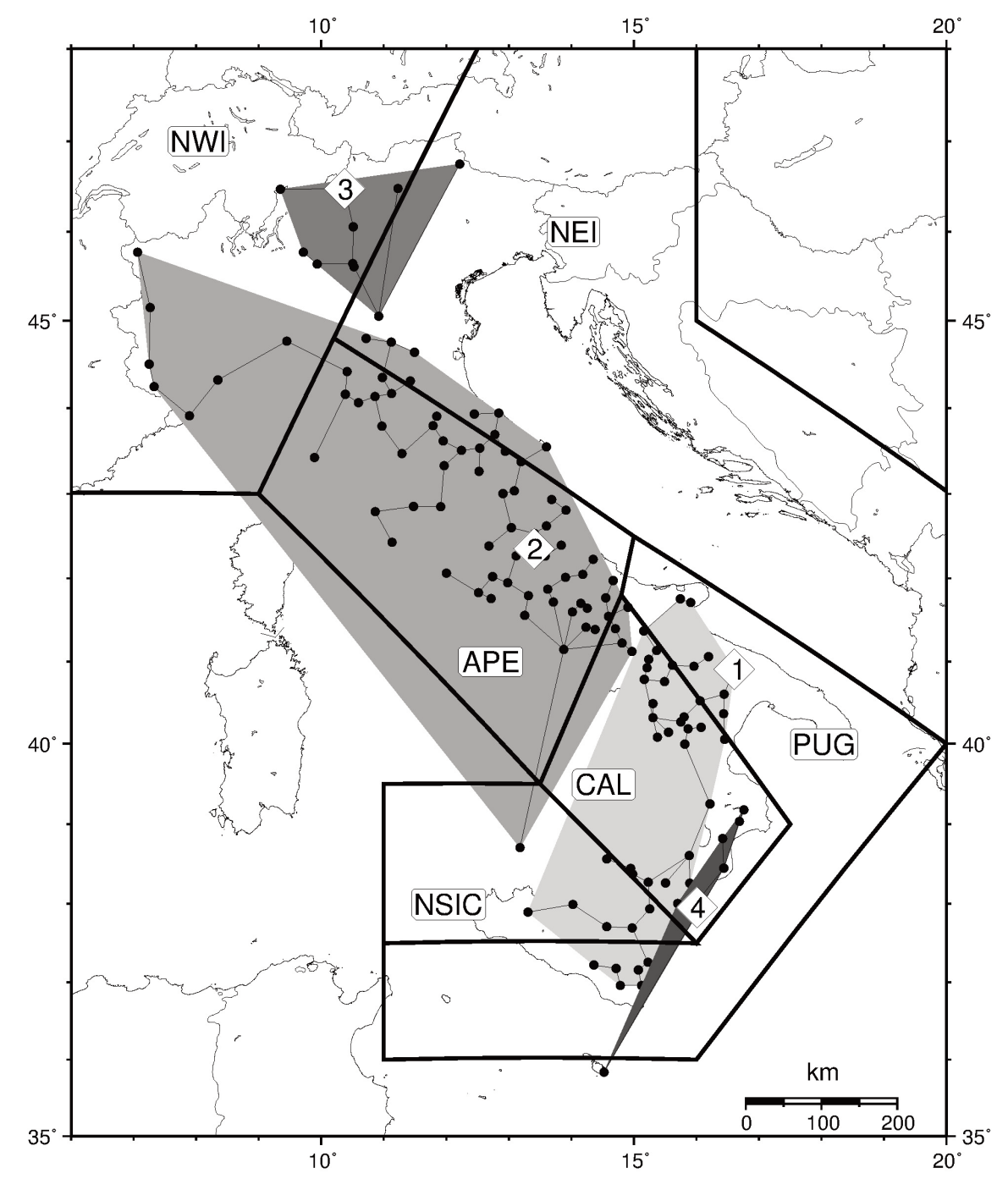

Figure 7. From [Bragato 2009]: seismic zones of homogeneous seismic behavior adopted by Michelini et al. [2008] (polygons delimited by black lines named NWI, NEI, APE, PUG, CAL and NSIC, respectively) and Bragato [2009] (grey areas enumerated 1-4). The dots and the links are the epicenters of the earthquakes and the corresponding connections used for the automatic seismic zonation by [Bragato 2009]. 


\section{Pier Luigi Bragato et al.}

In order to further the analysis, we investigated the existence of systematic geographical differences in terms of site effects. For this purpose, we exploited the national-wide data set of soil classes developed by Forte et al. [2019] and accessible by means of their program SSC-Italy (Seismic Soil Class-Italy, available at http://wpage.unina.it/iuniervo/SSC-Italy.zip). The dataset provides the average shear-wave velocities of the upper $30 \mathrm{~m}, \mathrm{~V}_{\mathrm{S}, 30}$ [Borcherdt, 1994], for a dense grid of points. From $\mathrm{V}_{\mathrm{S}, 30}$ it is possible to derive the classification of the soils in the four A-D categories of the Italian building code [CS.LL.PP., 2018]. Going from class A to D the soils become softer and should in general indicate areas where damage and loss of life could be more concentrated. Based on the soil classification, one could ideally correlate the number of deaths in each locality with the corresponding soil type. However, for most earthquakes we only have the overall number of victims and lack specific details for each locality. For an alternative, indirect assessment, we analyzed the differences among soil types in the municipalities that are classified at the highest levels of seismic hazard by the Italian seismic regulation. Figure 8 shows the distribution by soil classes for the municipalities in the seismic zones 1 and 2 located north and south of $42.95^{\circ} \mathrm{N}$ (the $\mathrm{E}$ class is also included for thin deposits on bed-rock). In general, for the seismic zone 1 the characteristics of the soils are better in southern Italy than in northern Italy ( $76 \%$ vs. $54 \%$ of municipalities with soils in either class A or B). Similar considerations apply to the seismic zone 2, where the proportion of A-B soils is $68 \%$ and $54 \%$ in southern and northern Italy, respectively. This simplified analysis suggests that soil conditions do not contribute to the greater earthquake lethality observed in southern Italy.

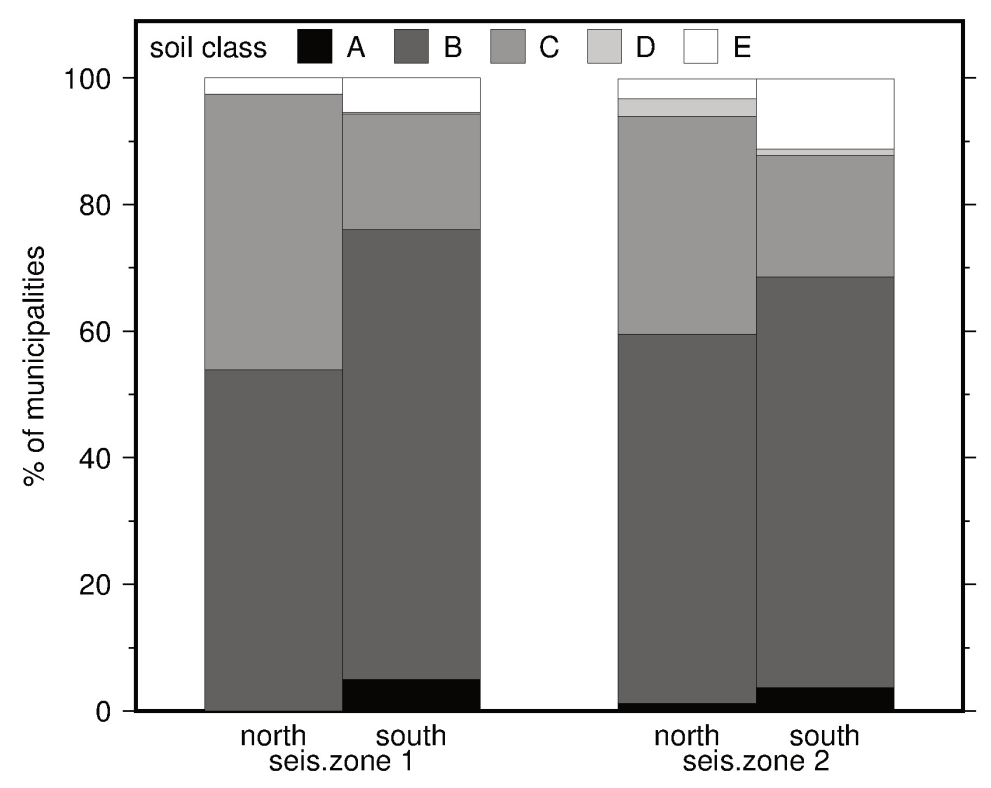

Figure 8. Percentage of municipalities in each soil class of the Italian seismic regulation (A-E) considering separately the towns located north and south of $42.95^{\circ} \mathrm{N}$, and belonging to the seismic zones 1 (highest seismic hazard) and 2 (intermediate seismic hazard). The soil class is that close to the city hall.

\subsection{Variation of earthquake mortality over the years}

We analyzed the time evolution of the geographical divide, looking at what happened before and after 1918 (Figure 9). In the northern sector both time periods (Figures 9a and 9b) are stably dominated by class-B earthquakes, more clearly over magnitude $5.5: 75 \%$ before $1918,77 \%$ in the last century. The bimodality is not eliminated in the southern sector. It is particularly marked before 1918 (Figure 9c) with a clear predominance of class-A earthquakes (23 out of 29 earthquakes, 79\%). The bimodality is still present after 1918 (Figure 9d), although with a general equilibrium between class-A and class-B earthquakes ( $55 \%$ and $45 \%$, respectively). The equilibrium breaks for the 
five strongest earthquakes (all with $M w \geq 6.2$, evidenced by the dashed rectangle in Figure $9 \mathrm{~d}$ ), four of which ( $80 \%$ ) are in class A. Figure 9 also offers details for the the recent years: the three earthquakes of 2009, 2012 and 2016 are well aligned with the class dominating their respective area (class A for the earthquakes of 2009 and 2016 located south of $42.95^{\circ} \mathrm{N}$, class B for the earthquake of 2012 which occurred in the northern sector). In summary, the characteristics of mortality north and south of $42.95^{\circ} \mathrm{N}$ remains almost stable in time, especially for the stronger earthquakes.

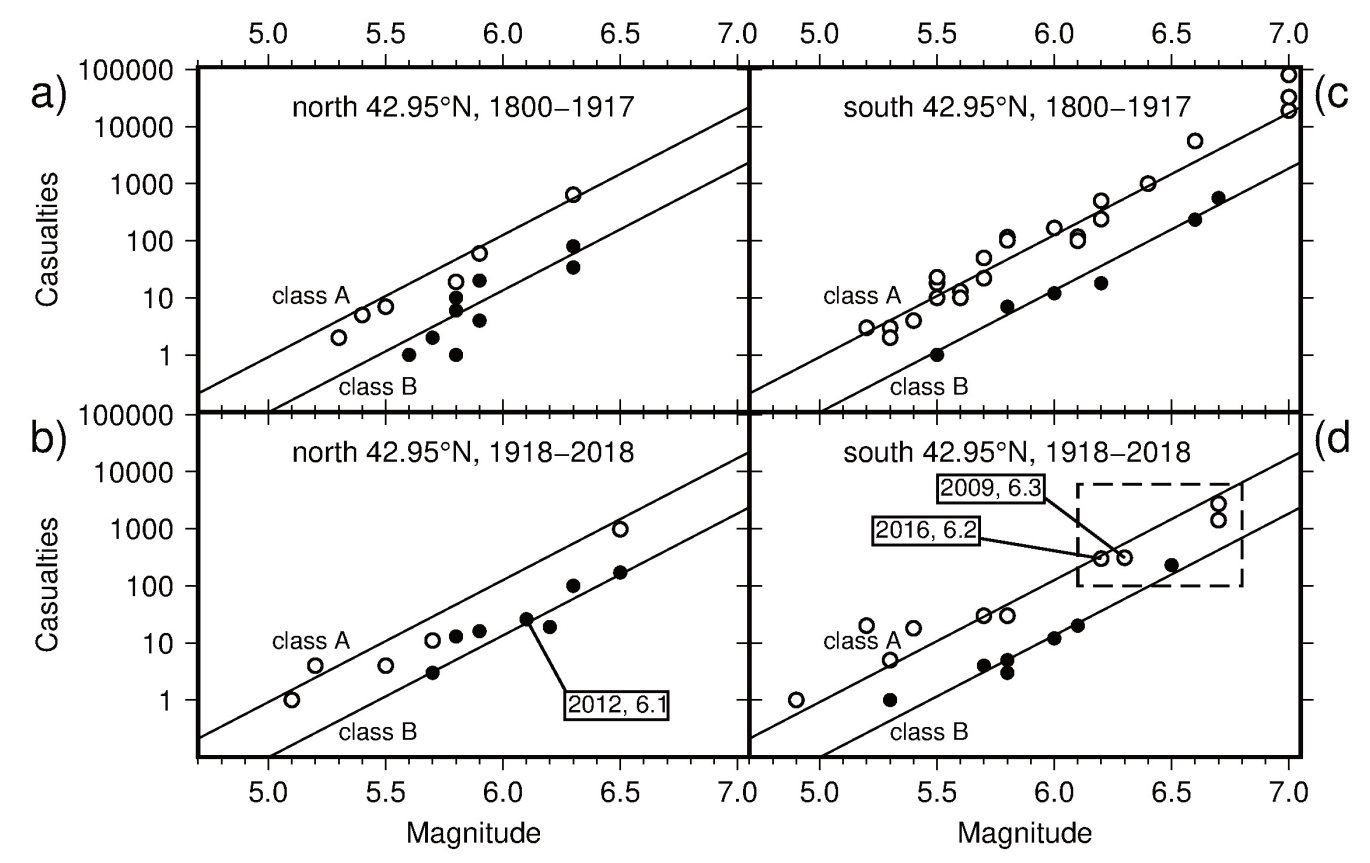

Figure 9. Comparison between the regression model (equation 2, the same lines of Fig. 5a) and data (magnitude and casualties) for different combinations of geographic area (north and south of $42.95^{\circ} \mathrm{N}$ ) and time period (before and after 1918). White and black circles: earthquakes in class A (most lethal) and B (less lethal), respectively. The dashed rectangle in the panel $\mathrm{d}$ ) evidences the earthquakes with magnitude $\mathrm{Mw} \geq 6.2$. The labels indicate the three earthquakes most recent.

\subsection{Earthquake mortality vs. time of day}

We analyzed the consequences of the earthquakes in relation to their time of occurrence within the day (for homogeneity we referred to the local winter time). The distribution of the events through the 24 hours is shown in Figure 10, where they are also classified according to their geographical area (north/south of $42.95^{\circ} \mathrm{N}$ ) and lethality (classes A and B in Figures 5a and 6). The origin time has been inserted as a further explanatory variable in the regression model in the form of day/night classification, trying different time intervals for the day (e.g. 07:00-22:00 or 05:00-24:00), but no improvement was obtained in terms of AICc. Nonetheless, Figure 10a provides important information: in northern Italy the class-A, most lethal earthquakes are almost absent in the time window 00:0005:00 (one out of 9 earthquakes, $11 \%$, compared to $50 \%$ in the rest of the day). This means that, in general, in this portion of the territory people are safer when sleeping at home. Differently, in southern Italy (Figure 10b) the same time window is dominated by class-A earthquakes (10 out of 13,77\%). In order to quantify the difference of night mortality, we repeated the two-class regression analysis (equation 2) with north/south grouping, considering only the earthquakes which occurred between 00:00 and 05:00 (Figure 11), obtaining $c=0.92$ ( $c=0.85$ for the larger time window 22:00-07:00). This means that on average, a nocturnal earthquake in southern Italy causes 8.3 times the number of victims than in northern Italy. This trend is confirmed by the three earthquakes most recent, which all occurred in the time period under consideration (Figure 11). 
a)

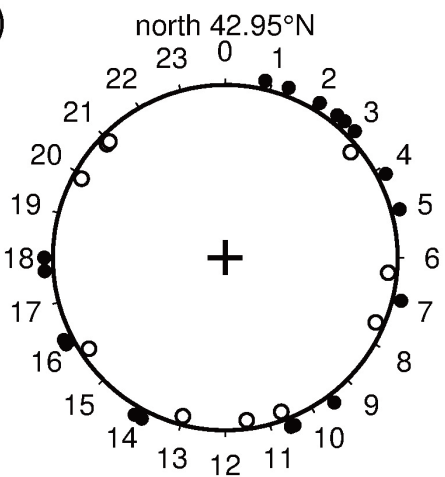

b)

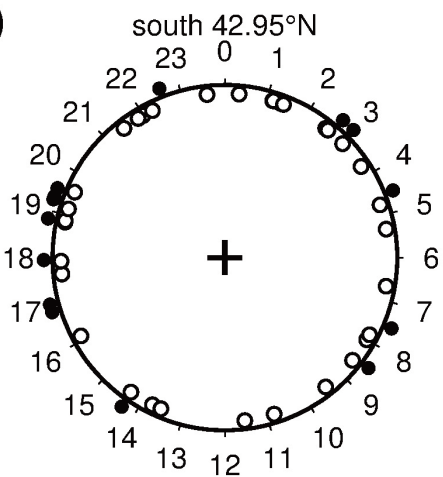

class $A \quad$ class $B$

Figure 10. Distribution of the earthquakes by class of lethality (A/B in Figs. 5a and 6), geographical area (north, south) and origin time (local winter time).

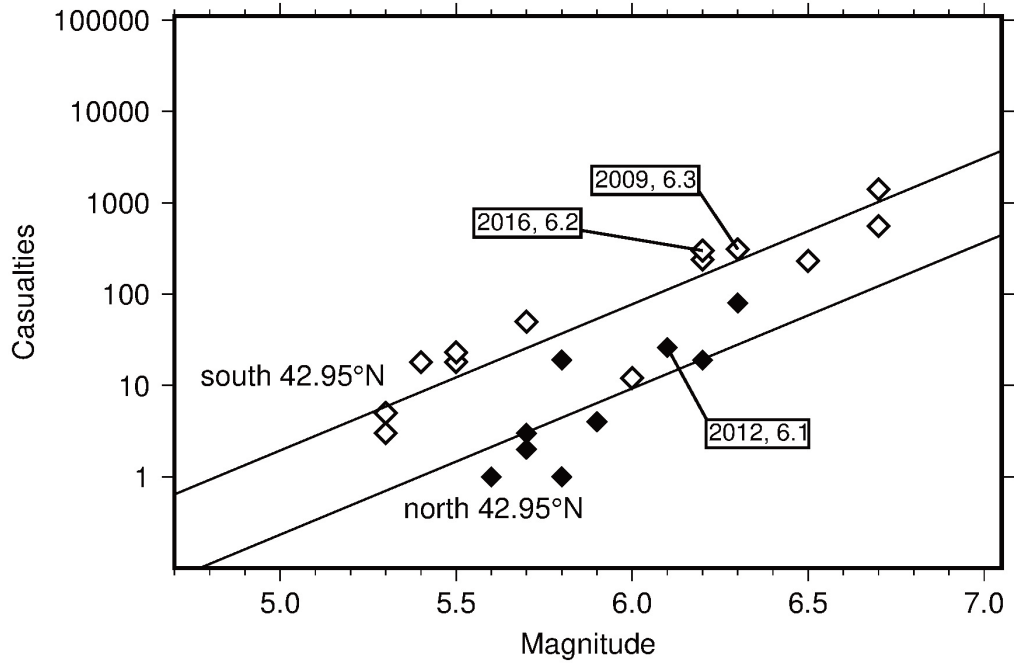

Figure 11. Data (magnitude and casualties) for the earthquakes occurred in the night (00:00-05:00 a.m. local winter time) north and south of $42.95^{\circ} \mathrm{N}$ (white and black diamonds, respectively). The straight lines are those estimated for this subset of data using the two-class regression model of equation 2 with north/south classification.

\subsection{Earthquake mortality vs. population density}

We explored the role of population density in explaining the observed earthquake mortality invariance and geographical divide. The evolution of the Italian population is known at the municipal level starting from the first national census of 1861 [ISTAT 1994 and updates from the successive censuses, data made available as CSV files by Tuttitalia.it, http://www.tuttitalia.it]. Since then, the Italian population has almost tripled, reaching 60 million inhabitants in the last census of 2011. It could be argued that such demographic development has negatively balanced the contemporary improvement of buildings, leading to the time invariance of mortality observed in our analysis. Unfortunately, this is not the case: mortality remained high despite the fact that a large part of the Italian territory with high seismic hazard has undergone a strong depopulation trend [ISTAT, 2019]. The trend is illustrated in Figure 12 (population index, 1901=1): differently from the rest of Italy, the municipalities classified in the most 
hazardous seismic zone 1 (thick black line in Figure 12) stopped their demographic expansion around 1951, to regress to the level of 1920 or, in the case of the small municipalities (less than 10,000 inhabitants in 2011) to the level of 1861 . Figure 13 shows what occurred in the municipalities most affected by the strongest earthquakes of the last 50 years (dotted lines: each municipality; thick black line: sum of inhabitants). In almost all the cases, at the time of the earthquake (dashed vertical line) the epicentral area was suffering depopulation (Emilia 2012, Figure 13c) or long-term demographic stabilization. The only exception was L'Aquila in 2009, characterized by an increasing trend (although lower than in the rest of Italy), with a population that at the time of the earthquake was $50 \%$ larger than in 1900 . Figures 12 and 13 refer to the population officially resident in the municipalities, not considering the short-term fluctuations due to temporary migrations and tourist flows marginal. To our knowledge, the only two significant exceptions are those of L'Aquila in 2009 and Central Italy in 2016. In the first case the number of residents did not include the university students, 45 of whom lost their life in the earthquake. According to the yearbook of the local University (Università degli Studi dell'Aquila 2009) there were 15,000 enrolled students, the largest part coming from other municipalities. Assuming that about half of them were present in L'Aquila the night of the earthquake, the total population of the city should be increased by $10-15 \%$. In the case of the Central Italy earthquake, $62 \%$ of the victims were not resident in the area ['L'elenco delle vittime riconosciute pubblicato dalle prefetture di Rieti e Ascoli Piceno", 2016], many of them hosted in old houses adapted as vacation homes. Based on this proportion, we estimate that the real population at the time of the earthquake was up to three times larger than in the census of 2011. Even with this correction, it was below the level of 1861 (Figure 13f).

Spatial differences in the population density can partially explain the north/south divide of the earthquake mortality. Figure 14 shows the demographic evolution of the municipalities located north and south of $42.95^{\circ} \mathrm{N}$ since 1861 and included either in category 1 or 2 of the national seismic regulation. In general, the population density in southern Italy is larger than in northern Italy, with a south/north density ratio that changes with time, reaching a maximum value near 1.5 for both seismic categories. We used such a ratio as a correction to re-estimate the average north/south divide (parameter $c$ in equation 2). More precisely, we reduced the number of victims of an earthquake which occurred in the south at the time $t$ by dividing this number by the corresponding south/north density ratio at time $t$. In doing so, it can be seen that about one third of the north/south gap is explained by the different population density. Even corrected for the demographic effect, the mortality in the south is twice that in the north (and about five times for the earthquakes occurring between 0:00 and 5:00 a.m.).

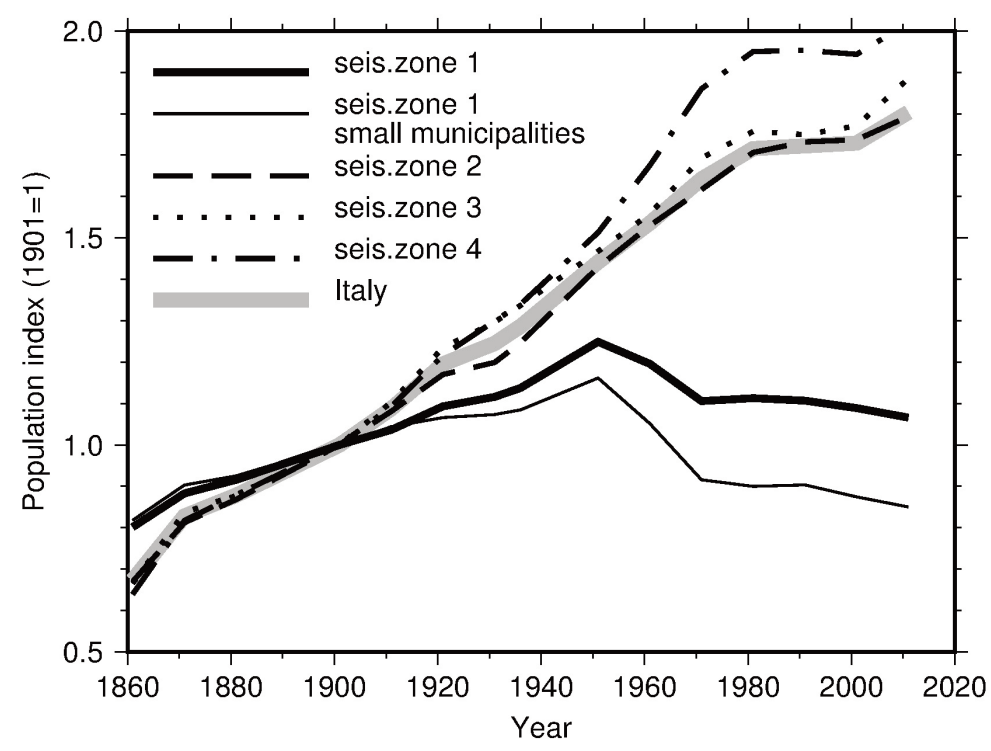

Figure 12. Trends of population since $1861(1901=1)$ for municipalities grouped according to their classification in the Italian seismic regulation (from 1, high seismic hazard, to 4, low hazard). The thin continuous line refers to small municipalities (less than 10,000 inhabitants) in class 1 . The thick grey line represents the evolution of the overall Italian population. 
Pier Luigi Bragato et al.
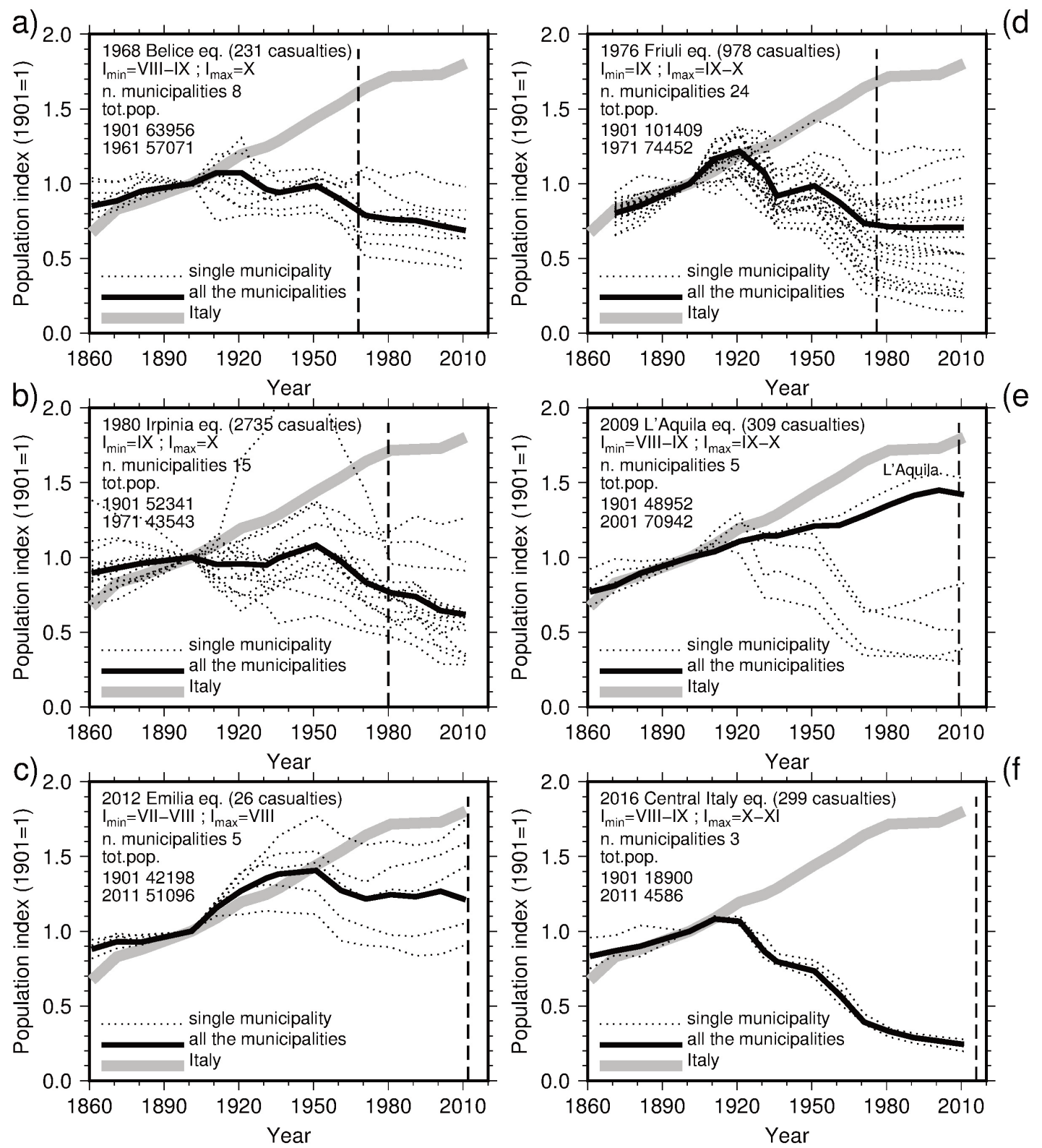

Figure 13. Trends of population since $1861(1901=1)$ in the areas hit by the strongest earthquakes occurred in Italy since 1968. The dashed lines correspond to the municipalities that suffered the heaviest damage for each earthquake (the range of macroseismic intensities Imin-Imax is reported in each panel). The thick black line refers to the sum of population of the selected municipalities, while the thick grey line represents the evolution of the Italian population. 


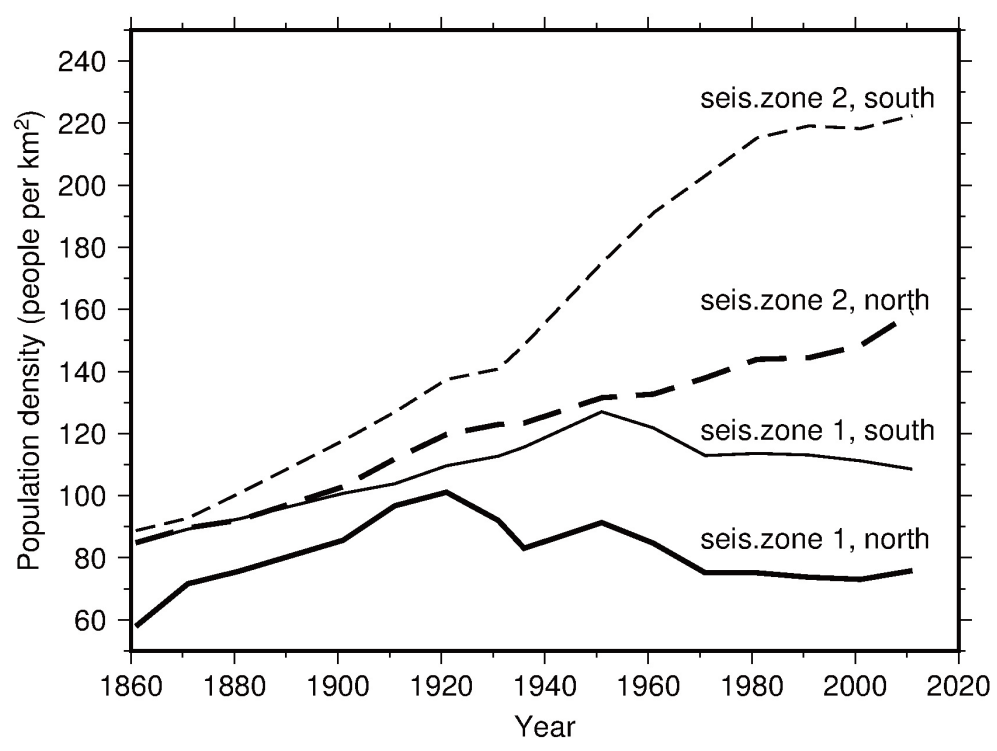

Figure 14. Variations of the density of population for municipalities classified in the categories 1 and 2 of the Italian seismic regulation and located north and south of $42.95^{\circ} \mathrm{N}$.

\section{Discussion}

As expected, the previous analysis indicates that the magnitude of the earthquakes is largely the main factor affecting the mortality due to an earthquake. A simple log-linear relationship with the earthquakes grouped in two classes (equation 2 and Figure 5a) covers two units of magnitude sufficiently well (from 5 to 7 ), with a standard deviation of the residual $\sigma=0.28$. However, the bimodality of the residuals has no univocal explanation. Part of it has a geographical origin, with the class-A most lethal earthquakes mainly concentrated in southern Italy.

The most prominent feature emerging from our analysis is the increased geographical divide for the nocturnal earthquakes (Figure 11). On average, for the same magnitude they kill 8.3 times more in southern Italy than in northern Italy. Corrected for population density, this proportion decreases to 5.3 times, which is still high. During the night, the role of the residential buildings is predominant in respect to the other factors, such as the strength of public buildings (e.g., schools, churches and factories). The behavior of people during the shaking also has a reduced impact, as their reaction capacity is very low. A thorough analysis of the space/time relationship between the strength of the residential buildings and the nocturnal mortality of earthquakes would require detailed data (age, material and structural characteristics of the buildings) at the national level and for a long time period, which are currently not available. We tried to perform a simplified analysis using aggregated indexes on the average quality of the houses provided by a survey conducted in 1934 [ISTAT, 1934] and by the national censuses carried out since 2001 [ISTAT, 2004, 2011a]. The 1934 report classified the rural houses according to four categories (habitable; habitable with minor repairs; habitable with major repairs; to be demolished) in order to improve or rebuild them. The classification was carried out qualitatively by local doctors, based on clearly observable hygienic and building conditions. The report does not mention the structural characteristics of the houses, but it seems realistic to assume that a house not suitable for living is poorly constructed or lacks sufficient maintenance, so that it is less resistant to earthquakes. The focus on the rural houses was not a limit, because at that time Italy was mainly an agricultural country. Figure 15, drawn from the cited report, shows the percentage of rural houses that according to the survey should have been demolished in each province of the country. It evidences a north-south transition, which resembles that of the earthquake mortality depicted in Figure 6. Looking at more recent data, we analyzed the percentage of occupied residential buildings that have undergone some maintenance or restorations during the decade 19912001 [ISTAT, 2004]. These operations were performed in large percentage in northern-eastern Italy $(53,7 \%)$ and to 
Pier Luigi Bragato et al.

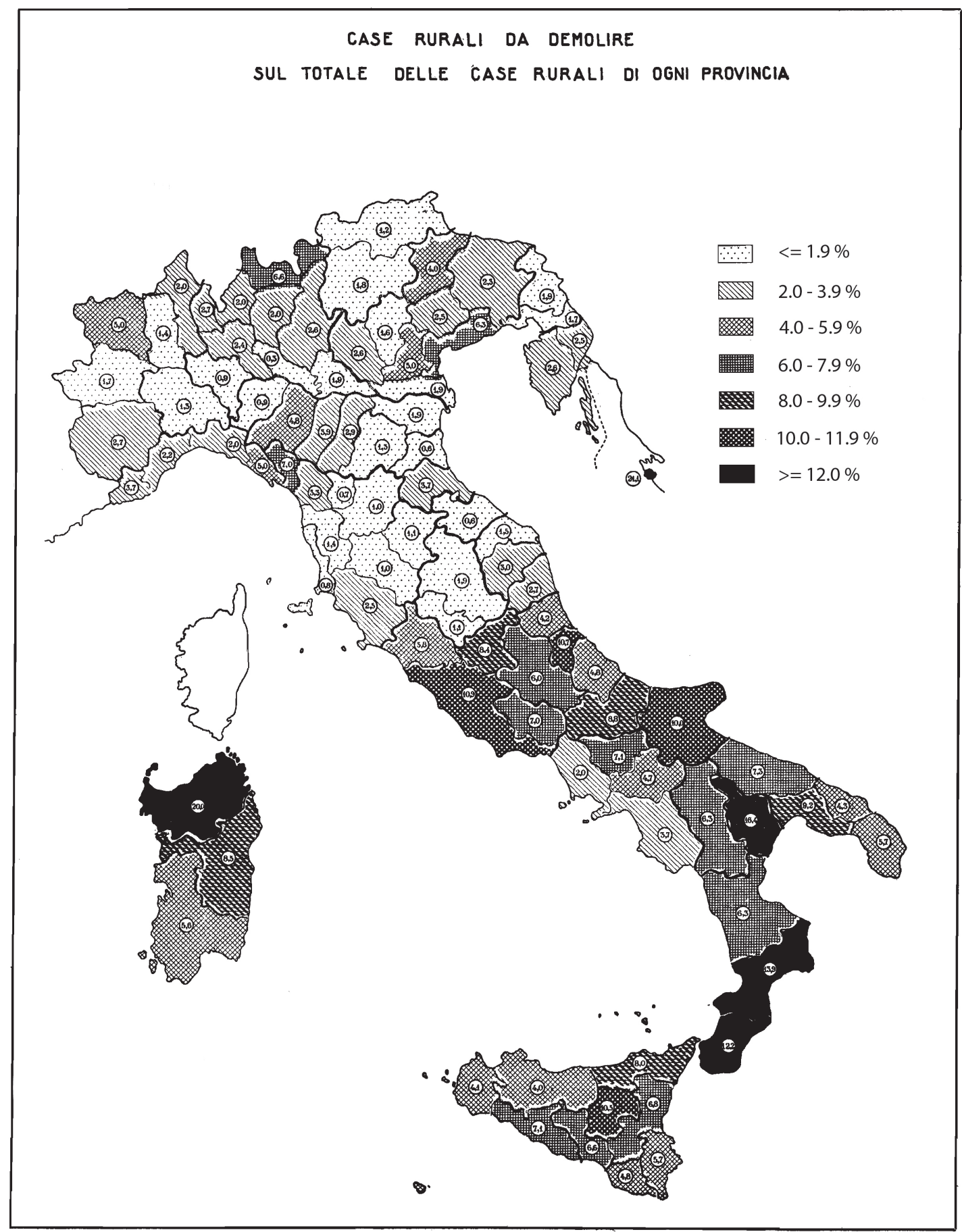

Figure 15. Percentage of rural houses in bad conditions to be demolished according to (ISTAT 1934). 


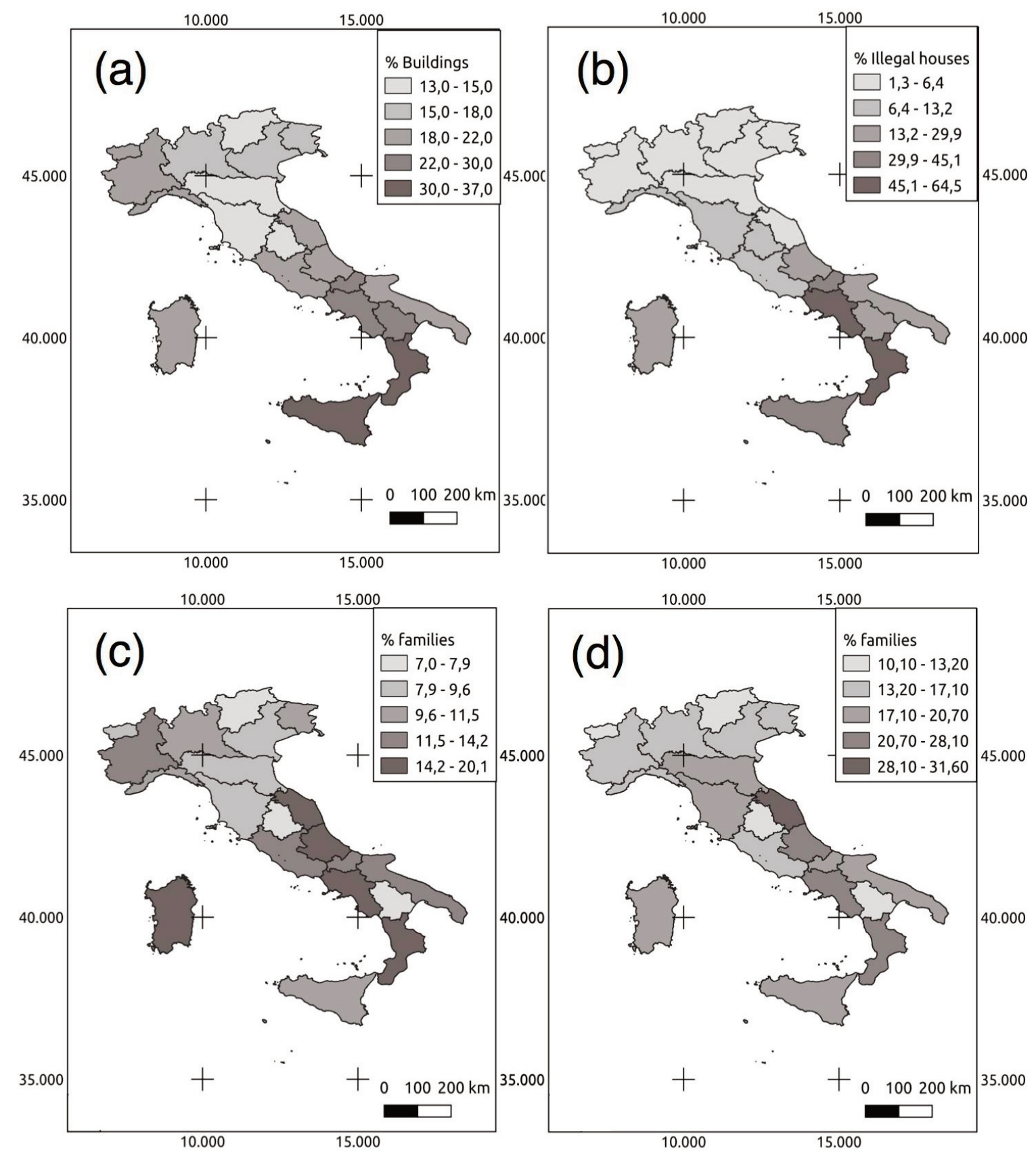

Figure 16. Statistics about buildings in the Italian regions drawn from the last general national census (ISTAT 2011a): a) percentage of residential masonry buildings in poor or bad maintenance state; b) number of illegal houses for 100 new legal houses; c) percentage of families living in buildings with existing damages; d) percentage of families living in buildings with humidity problems. The percentages in c) and d) are calculated over 100 families with the same characteristics. Furthermore, for few regions (Trentino-Alto Adige, Valle D’Aosta, Molise, and Basilicata) values have limited statistical value (see ISTAT metadata for details on the survey methodology). 


\section{Pier Luigi Bragato et al.}

a lower extent in southern Italy (35,9\%), so that the north-south house-quality divide has increased with time. The last general national census [ISTAT 2011a] confirms that the poorly maintained masonry buildings are mainly concentrated in southern Italy (Figure 16a). This fact is particularly important because masonry buildings are often predominant in small mountain towns (the north/south contrast is less evident for reinforced concrete buildings). Furthermore, according to data gathered within the EU-SILC framework (European Union Statistics on Income and Living Conditions), implemented at the Italian scale by ISTAT [https://www.istat.it/it/archivio/5663], in 2011 a substantial number of families were still living in houses with some kind of damage (Figure 16c) or humidity problems (Figure 16d). According to Figure 16, there is a north/south contrast in terms of damaged houses (Figure 16c) while the humidity problems are more homogeneous throughout the country (Figure 16d). The presence of damage, regardless of its entity, suggests that a building's response to seismic action can be worsened, while prolonged exposure to humidity can reduce the mechanical resistance of masonry walls. Thus, both factors can substantially increase injuries, regardless of the presence of structural damage, and may contribute to the fatalities [Peek-Asa et al., 2003]. Note that according to the ISTAT census, the worse conditions are found in small municipalities (with less than 2,000 inhabitants).

Another index related to the quality of residential buildings and their expected seismic response is the percentage of illegal buildings. It can be conservatively assumed that illegal buildings are made of poor materials and do not adhere to any seismic building code, thus having design flaws (if designed) with consequent low resistance to earthquakes. The impact of illegal buildings and subsequent low building standards has been pointed out as a cause of building collapse in the case of earthquakes, in particular in Italy and Turkey [Bakır and Boduroglu, 2002; Binici, 2006; Özerdem and Rufini, 2012; Valensise et al., 2017]. The percentage of illegal houses in each region of Italy is shown in Figure 16b. Even in this case there is a contrast between northern and southern regions that matches that of earthquake mortality. This aspect is particularly relevant for more recent buildings, such as those constructed after the Second World War and during the construction boom in Italy. We can therefore conclude that the quality and maintenance of buildings and their seismic performance is an ongoing problem and still needs to be addressed in order to avoid significant consequences in the future. This aspect, together with others mentioned and discussed in this work, may therefore contribute to explain the observed differences in earthquake casualties and the geographic divide of the nighttime mortality.

Finally, according to Frigerio et al. [2016], socio-economic indicators in Italy such as employment, education and age are strongly related to social vulnerability and seismic hazard. The authors underline the differences between northern and southern regions. For example, the percentage of families with conditions of "relative poverty" in Italy in 2011 [ISTAT, 2011a], based on the International Standard of Poverty Line (ISPL) is 3-10\% in the northern regions and more than $20 \%$ in some southern regions. A comprehensive picture is provided by the social vulnerability index of 2011, defined by ISTAT [2011b] on the basis of several socio-economic indicators (e.g., literacy level, families in poor housing and home conditions, unemployment rate, economic factors): also, in this case the north/south divide is confirmed, with the northern regions having lower social vulnerability.

\section{Conclusions}

During the last century we have observed a progressive reduction of the number of victims caused by earthquakes in Italy: from tens of thousands at the beginning of the $20^{\text {th }}$ century (1908, Calabria-Messina; 1915, Marsica), to thousands in the seismic cycle of around 1970 (1968, Belice; 1976, Friuli; 1980, Irpinia), to hundreds in the last seismic cycle of the last decade (2009, L’Aquila,; 2012, Emilia; 2016, Central Italy). The number of victims is still high and every effort should be made to further reduce them. Nonetheless, at first glance the decreasing trend might be ascribed to the progressive improvement of buildings. However, our work provides a different view, according to which the reduction so far observed is mainly attributable to two simultaneous unintentional factors, which are not guaranteed for the future. The first factor is the decreasing trend of seismicity observed in the last decades, concerning both the number and the energy of the earthquakes (Figures 2 and 3 and references given in Section 2). The second factor is depopulation of the areas at high seismic risk. The lethality of strong earthquakes of given magnitude has remained substantially unchanged over the last two centuries, with events of magnitude around 6 that are capable of causing 300 fatalities. We have also evidenced greater lethality in southern Italy, especially for earthquakes occurring at night, when people mostly rely on the strength of their houses for their survival. Such a 
geographical divide is the product of a combination of many factors and, among them, may be related to population density and type, occupation and location of residential buildings. In addition, the analysis of the quality and maintenance level of residential buildings based on the last decades show a strong difference between northern and southern Italy, which may have been inherited from the past. The results of our analysis underline the importance of increasing societal resilience and the strong relationship between resilience and vulnerability of the building stock, also stressed by Vona et al. [2015]. In particular, the application of current seismic regulations and the retrofitting of existing buildings should be considered a priority in order to improve their seismic response during future events. In conclusion, the adoption of good practices such as high qualitative standards in the design, construction and maintenance of buildings and rational territorial planning is fundamental for a significant reduction in seismic vulnerability and, subsequently, earthquake mortality. Governments have a strong influence on mortality prevention [Keefer et al., 2011] and should therefore play a substantial role in improving the societal response to seismic events.

\section{Data and sharing resources}

The earthquake catalog CFTI5Med [Guidoboni et al. 2018, 2019] was available at the URL http://storing.ingv.it/cfti/cfti5 (last access June 2020). The earthquake catalog CPTI15 v2.0 [Rovida et al. 2019, 2020] was downloaded from the web site https://emidius.mi.ingv.it/CPTI15-DBMI15 (last access June 2020). Census data since 1861 were published by ISTAT (1994 and updates from the successive censuses) and provided in electronic form (CSV files) by Tuttitalia.it (http://www.tuttitalia.it). The grid of seismic soil classifications at the national level [Forte et al., 2019] was available at the URL http://wpage.unina.it/iuniervo/SSC-Italy.zip (last access June 2020). The data about buildings of the last general national census [ISTAT 2011a], were downloaded from https://www.istat.it/it/censimenti-permanenti/censimenti-precedenti/popolazione-e-abitazioni/popolazione-2011 (last access June 2020). The statistical analysis was performed using R software version 3.3.3 [R Core Team, 2017] http://www.R-project.org (last access June 2020). The figures 1-14 were made using Generic Mapping Tools version 5.1.1 [Wessel et al. 2013] available at http://www.soest.hawaii.edu/gmt (last access June 2020).

Acknowledgements. We thank the Editor Irene Molinari and two anonymous reviewers for their constructive critical reading.

\section{References}

Akaike, H. (1977). On entropy maximization principle. In Krishnaiah, P.R. (Ed.), Proceedings of the symposium on applications of statistics (pp. 27-47), North-Holland, Amsterdam.

Alexander, D. and M. Magni (2013). Mortality in the L'Aquila (central Italy) earthquake of 6 april 2009, PLoS Currents Disasters, 5, e50585b8e6efd1.

Ambraseys, N. and R. Bilham (2011). Corruption kills, Nature 469, 153-155.

Bakır, P.G. and H. Boduroglu (2002). Earthquake risk and hazard mitigation in Turkey, Earthq. Spectra 18, 427-447.

Bellicoso, A. (2011). Italian anti-seismic legislation and building restoration, Int. Journal for Housing Science 35, 137-147.

Bilham, R. (2009). The seismic future of cities, Bull. Earthq. Eng. 7, 839-887.

Binici, H. (2006). March 12 and June 6, 2005 Bingol-Karliova earthquakes and the damages caused by the material quality and low workmanship in the recent earthquakes, Eng. Fail. Anal. 14, 233-238.

Borcherdt, R.D. (1994). Estimates of site-dependent response spectra for design (methodology and justification), Earthq. Spectra 10, 617-653.

Boschi, E., G. Ferrari, P. Gasperini, E. Guidoboni, G. Smriglio and G. Valensise (1995). Catalogo dei forti terremoti in Italia dal 461 a.C. al 1980, ING and SGA, Bologna (in Italian).

Bragato, P.L. (2009). Assessing regional and site-dependent variability of ground motions for ShakeMap implementation in Italy, Bull. Seismol. Soc. Am. 99, 2950-2960.

Bragato, P.L. (2015). Italian seismicity and Vesuvius' eruptions synchronize on a quasi 60-year oscillation, Earth 


\section{Pier Luigi Bragato et al.}

Space Sci. 2, 134-143.

Bragato, P.L. (2017a). A statistical investigation on a seismic transient occurred in Italy between the 17th and the 20th century, Pure Appl. Geophys. 174, 907-923.

Bragato, P.L. (2017b). Periodicity of strong seismicity in Italy: Schuster spectrum analysis extended to the destructive earthquakes of 2016, Pure Appl. Geophys. 174, 3725-3735.

Bragato, P.L. (2018) Correlation between seismic and volcanic activity at a large spatial scale in Italy: Examples from the Neapolitan volcanic district (Vesuvius volcano, southern Italy). - In: Aiello, G. (Ed.). Volcanoes Geological and Geophysical Setting, Theoretical Aspects and Numerical Modeling, Applications to Industry and Their Impact on the Human Health, IntechOpen, London, 19-33.

Bragato, P.L. and M. Sugan (2014). Decreasing rate of $M \geqslant 7$ earthquakes in the northern hemisphere since 1900, Seism. Res. Lett. 85, 1234-1242.

Bragato, P.L. and H. Holzhauser (2019). Observations on the connection between glacial phases, natural catastrophes and economic trends of the last millennium in Italy, The Holocene 29, 1322-1334.

Burnham, K. P., and D.R. Anderson (2002). Model selection and multimodel inference: a practical informationtheoretic approach (2nd ed.), Springer, New York.

CS.LL.PP. (2018). Decreto Ministeriale: norme tecniche per le costruzioni, Gazzetta Ufficiale della Repubblica Italiana, n. 42, 20 febbraio 2018, Suppl. Ordinario n. 8, Ist. Polig. e Zecca dello Stato S.p.a., Rome (in Italian).

Coburn, A.W., R.J.S. Spence and A. Pomonis (1992). Factors determining human casualty levels in earthquakes: mortality prediction in building collapse. In: Proceedings of the 10th World Conference on Earthquake Engineering, Madrid, July 1992, A.A. Balkema, Rotterdam.

Forte, G., E. Chioccarelli, M. De Falco, P. Cito, A. Santo and I. Iervolino (2019). Seismic soil classification of Italy based on surface geology and shear-wave velocity measurements, Soil Dyn. Earthq. Eng. 122, 79-93.

Frigerio, I., S. Ventura, D. Strigaro, M. Mattavelli, M. De Amicis, S. Mugnano and M. Boffi (2016). A GIS-based approach to identify the spatial variability of social vulnerability to seismic hazard in Italy, Appl. Geogr. 74, 12-22.

Gasperini, P., F. Bernardini, G. Valensise and E. Boschi (1999). Defining seismogenic sources from historical earthquake felt reports, Bull. Seism. Soc. Am. 89, 94-110.

Guidoboni, E. and G. Ferrari (2000). Historical variables of seismic effects: economic levels, demographic scales and building techniques, Ann. Geophys. 43, 687-705.

Guidoboni, E., G. Ferrari, D. Mariotti, A. Comastri, G. Tarabusi, G. Sgattoni and G. Valensise (2018). CFTI5Med, Catalogo dei Forti Terremoti in Italia (461 a.C.-1997) e nell'area Mediterranea (760 a.C.-1500), Istituto Nazionale di Geofisica e Vulcanologia (INGV), Rome. http://storing.ingv.it/cfti/cfti5/.

Guidoboni, E., G. Ferrari, G. Tarabusi, G. Sgattoni, A. Comastri, D. Mariotti, C. Ciuccarelli, M.G. Bianchi and G. Valensise (2019). CFTI5Med, the new release of the catalogue of strong earthquakes in Italy and in the Mediterranean area, Scientific Data 6, 80.

Gutiérrez, E., F. Taucer, T. De Groeve, D.H.A. Al-Khudhair and J.M. Zaldivar (2005). Analysis of worldwide earthquake mortality using multivariate demographic and seismic data, Am. J. Epidemiol. 161, 1151-1158.

ISTAT (1934). Indagine sulle case rurali in Italia. Ist. Poligrafico dello Stato, Rome, https://ebiblio.istat.it/digibib/ Demografia/IST7205IndcaseruraliItalia.pdf.

ISTAT (1994). Popolazione residente dei comuni. ISTAT, Rome, https://ebiblio.istat.it/digibib/Censimenti\%20popolazione/ Censimentipopolazioneresidentedal1861/RML0050288Pop_res_cens_1861_1991.pdf

ISTAT (2004). Edifici ed abitazioni - Censimento 2001. Dati definitivi. ISTAT, Rome, http://dawinci.istat.it/jsp/MD/ download/edifici_abitazione2004.pdf.

ISTAT (2011a). $15^{\circ}$ Censimento della popolazione e delle abitazioni 2011. ISTAT, Rome, https://www.istat.it/it/ censimenti-permanenti/censimenti-precedenti/popolazione-e-abitazioni/popolazione-2011

ISTAT (2011b). L'indice di vulnerabilità sociale e materiale. ISTAT, Rome, http://ottomilacensus.istat.it/fileadmin/ download/Indice_di_vulnerabilit\%C3\%A0_sociale_e_materiale.pdf.

ISTAT (2019). L'evoluzione demografica in Italia dall'Unità a oggi. ISTAT, Rome, https://www.istat.it/ it/archivio/225841.

Keefer, P., E. Neumayer and T. Plümper (2011). Earthquake propensity and the politics of mortality prevention, World Dev. 9, 1530-1541.

"L’elenco delle vittime riconosciute pubblicato dalle prefetture di Rieti e Ascoli Piceno" (2016, August 26, last modified August 30), Corriere della Sera. https://www.corriere.it/cronache/16_agosto_26/elenco-vittime- 
riconosciute-pubblicato-prefetture-rieti-ascoli-piceno-4ae998be-6bbc-11e6-8bdd-2a860cc068c8.shtml

Michelini, A., L. Faenza, V. Lauciani and L. Malagnini (2008). ShakeMap implementation in Italy, Seism. Res. Lett. 79, 688-697.

Özerdem, A. and G. Rufini (2012). L’Aquila’s reconstruction challenges: has Italy learned form its previous earthquake disasters? Disasters 37, 119-143.

Peek-Asa, C., M. Ramirez, H. Seligson and K. Shoaf (2003). Seismic, structural and individual factors associated with earthquake related injury, Inj. Prev. 9, 62-66.

Pondrelli, S., S. Salimbeni, A. Morelli, G. Ekstrm, L. Postpischl, G. Vannucci and E. Boschi (2011). EuropeanMediterranean Regional Centroid Moment Tensor Catalog: solutions for 2005-2008, Phys. Earth Planet. Int. 185, 74-81.

R Core Team (2013), R: A language and environment for statistical computing, R Foundation for Statistical Computing, Vienna, Austria. URL http://www.R-project.org/.

Rovida A., M. Locati, R. Camassi, B. Lolli and P. Gasperini (2019). Catalogo Parametrico dei Terremoti Italiani (CPTI15), versione 2.0, Istituto Nazionale di Geofisica e Vulcanologia (INGV), Rome, https://doi.org/10.13127/ CPTI/CPTI15.2

Rovida A., M. Locati, R. Camassi, B. Lolli and P. Gasperini (2020). The Italian earthquake catalogue CPTI15, Bulletin of Earthquake Engineering, https://doi.org/10.1007/s10518-020-00818-y.

Schwarz, G. (1978). Estimating the dimension of a model, Ann. Stat., 6, 461-464.

Spence, R. (2007). Saving lives in earthquakes: successes and failures in seismic protection since 1960, Bull. Earthq. Eng. 5, 139-251.

Stucchi, M., C. Meletti, V. Montaldo, H. Crowley, G.M: Calvi and E. Boschi (2011), Seismic hazard assessment (20032009) for the Italian building code, Bull. Seismol. Soc. Am. 101, 1885-1911.

Taboga, M. (2012), Lectures on Probability Theory and Mathematical Statistics, CreateSpace Independent Publishing Platform.

Università degli Studi dell’Aquila (2009). Annuario 2008-2009. Edizioni L’Una, L’Aquila.

Valensise, G., G. Tarabusi, E. Guidoboni and G. Ferrari (2017). The forgotten vulnerability: A geology- and historybased approach for ranking the seismic risk of earthquake-prone communities of the Italian Apennines, Int. J. Disaster Risk Reduct. 25, 289-300.

Vona, M., P. Harabaglia, and B. Murgante (2016). Thinking about resilient cities: studying Italian earthquakes, Proceedings of the Institution of Civil Engineers Urban Design and Planning, 169, 185-199.

Wessel, P., W.H.F. Smith, R. Scharroo, J. Luis and F. Wobbe (2013). Generic Mapping Tools: Improved version released, Eos Trans. AGU 94, 409-410. 